This is an electronic version of an article published in Miller, J. P., \& Nozawa, A. (2002). Meditating teachers: A qualitative study. Journal of In-Service Education, 28(1), 179-192. Cognition and Instruction is available online at: www.tandfonline.com with http://www.informaworld.com/openurl?genre=article\&issn=13 $\underline{67-4587 \& \text { volume }=28 \& \text { issue }=1 \& \text { spage }=179}$

\title{
Meditating Teachers: A Qualitative Study
}

\author{
John P. Miller \\ and \\ Ayako Nozawa \\ The Ontario Institute for Studies in Education at \\ the University of Toronto
}

Pre-service and in-service professional development for teachers has tended to focus on technique and theory. What often is missing is developing the elusive quality of presence. Yet when we look back on teachers that have had an impact on us it is exactly this quality of presence that has touched us most deeply. With reference to teachers Emerson once wrote: "What we are we teach. . According to the depth from which you draw our life, such is the depth not only of your strenuous effort but of your manners and your presence." How can we draw depth into our life to nurture our presence as teachers? One possible approach is through contemplative practices such as meditation. (Miller, 1994)

Since 1988 the senior author has required students in his graduate courses to meditate as part of the course requirements. These are courses for experienced teachers 
in the area of holistic education. The rationale for this process is based on several principles in an attempt to move away from just "head" learning to nurturing presence and being.

One important reason for requiring meditation is that it can be a form of selflearning. For example, insight, or vipassana, meditation is based on the notion that we can learn and grow by simply mindfully watching our own experience. As we notice our own thoughts and agendas, we can gain deeper insight into ourselves and the nature of experience. In this context meditation is a form on inquiry. In contrast, the model for most learning at the university level is that the professor and the text are the authority and the student must learn from these authorities. Meditation provides one alternative to this model and instead recognizes that we can learn from ourselves and our own experience.

Another reason for engaging in contemplation is that it allows students to deal with the stresses in their lives. Research indicates that meditation is an effective tool in enhancing physical and mental well being (Benson, 1976; Walsh, 1999) and given the pressures that students face today this aspect of meditation should not be overlooked. The vast majority of students in classes taught by the senior author have seen the positive effects of contemplative practice in simply being able to address stressful events that come up in their lives. For example consider the comments of a secondary school vice-principal who faced many stressful events during the day. He wrote in his journal that as the pressures of his job increase he finds the "need to engage in meditation more frequently."

Finally, meditation is important to how we approach teaching. If teaching is ego-based it can become a frustrating series of mini-battles with students. The classroom becomes focused around the issue of control. If we teach from our original self (e.g. our 
Buddha nature), teaching becomes a fulfilling and enriching experience. Robert Griffin (1977) summarizes this very well:

You do not feel set off against them [the students] or competitive with them. You see yourself in students and them in you. You move easily, are more relaxed, and seem less threatening to students. You are less compulsive, less rigid in your thoughts and actions. You are not so tense. You do not seem to be in a grim win-or-lose contest when teaching (p. 79).

When we teach mostly from our egos, our work inevitably becomes tense and frustrating; conversely when we teach from the original self our work becomes and act of joy and delight. Teaching from this deeper place, we experience connections with our students and our colleagues. The rationale for Self-based teaching has been explained in other contexts (Miller, 1993; Miller, 1994; Miller, 1995).

\section{Introducing Meditation to Teachers}

As Coordinator of a graduate specialization in Holistic and Aesthetic Education, the senior author teaches three courses: The Holistic Curriculum, The Teacher as Contemplative Practitioner and Spirituality in Education. In two of these courses students are required to do some form of meditation. The requirement is based on the premise that teaching should come from the original self rather than the ego. Ego based 
teaching ultimately reinforces our sense of separateness and suffering. It is emphasized in the courses that when we teach from the original self we gradually experience more moments of communion with our students. Through meditation we can experience moments of deep inner joy in teaching as we connect with our students in profound and subtle ways. Holistic education can be defined in many ways, however, one definition worth examining in this context is simply that holistic education releases the human heart. Meditation is fundamental to that release. One student in the study examined in this paper noted that after doing the meditation she was able to express love to others more easily.

Students are introduced to six different types of meditation which include: meditation on the breath, lovingkindness (sending thoughts of peace and wellness to self and others), mantra, movement (e.g. walking), visualization, and contemplation on poetry or sacred texts. Some students work out their own forms and integrate meditation with their own spiritual and religious practice. Although sitting meditation is encouraged, some students do movement meditation. For example, one student swam every day as he approached swimming from a meditative stance. Whatever form students choose, meditation can be seen as letting go of the calculating mind and opening to the listening mind that tends to be characterized by a relaxed alertness. Once the students have settled on a method they are encouraged to work up to about 30-minutes a day of meditation practice. The instructor keeps in touch with each student through a journal they keep on their practice. He also introduces students to the Buddhist lovingkindness meditation where thoughts of well-being are sent to oneself and others. Each class begins with this meditation and students are encouraged to begin or end their own individual meditation with it. Finally, students are also introduced to mindfulness practice which is being 
present in the moment in daily life. This means focusing on what we are doing without falling into automatic pilot where we can function without awareness. Mindfulness leads to deep attention.

To date over 1000 students have been introduced to meditation practice in these courses. Only two students have asked not to do the assignment as one student had been sexually abused a year before and did not feel comfortable with the practice. The other student was a Christian fundamentalist. So far there has not been a student who has had an overall negative experience with the practice during the course. Most of the students are women $(80 \%)$ in their 30 's or 40 's. While most of the students come from Ontario, there have also been students from Brazil, China, Indonesia, Iran, Italy, Jamaica, Lebanon, Japan, Kenya, Korea and Malta.

Students are asked to meditate each day for six weeks. In the beginning they meditate for about 10 to 15 minutes a day and by the end of the six weeks they are encouraged to meditate 20-30minutes each day. Students are required to keep a journal which focuses on how the process of meditation is going (e.g. how the concentration and focus are going, how the body is feeling, etc.). The journals also focus on how meditation has affected them. Some of themes have included

1) Giving themselves permission to be alone and enjoy their own company;

2) Increased listening capacities;

3) Feeling increased energy;

4) Being less reactive to situations and generally experiencing greater calm and clarity. 
At the end of the process they write a reflective summary of the experience. Below are some excerpts from these summaries. One woman who has dealt with illness writes:

When I meditate I concentrate on the internal organs and the sensations they feel. I practice lovingkindness to my internal organs and actually speak to them. This seems strange but effective. I ask them to forgive me for not listening earlier to their signals of exhaustion or distress. . .

Meditation offers a tremendous sense of release. It is my own sanctuary and anchor during times of stress. I relish the fact that I can detach during times of stress and anxiety and practice being in the moment. I can focus on my present surroundings and be mindful. . . .

I am aware of my yin/yang or feminine/masculine side. My masculine side is flourishing because I'm allowing it the space to speak to me during meditation. This has given me more confidence.

My heart hungers for beauty in nature and I have become more aware and mindful. My senses are acute and feed my soul when I am in the park. It is almost as if I reach another state of being-the smell of the earth and dried leaves, the coolness of the breeze, the touch of bark and leaves, the gentle warmth of the sun, the ducks and blue herons in the pond. .. .

Most important is the sacredness of human life. I tell my husband and children that they are so sacred. Sometimes I look at total stranger's walk, clothing or mannerisms. Something about that person moves me intuitively. . . .I am overcome 
with a sense of compassion and love that is unexplainable. Meditation allows me to be me without any conditions.

Another woman who is secondary school vice principal wrote:

The act of meditation has been an inner transformation of an outer manifestation, in other words, my physical change in behaviour is reflected in my change in awareness and intentionality. The other day my husband said, "You are not the same as you used to be. Something has changed in the last month or so. You aren't on an intense mission all the time."

I had never stopped and sat down to do nothing, let alone sat down to not even think. . . .Throughout this assignment I always meditated longer than I expected. Amazingly, I seem to have more time for everything without running frantically to get things done....

One thing that stood out for me was that I had tears during my most intense meditations. Sometimes the tears would wet my eyes and other time they would roll down my face. I got sick two weeks into meditation and during this time I found that the tears were profuse and my breathing was much deeper as though I was expelling toxins. I found this particularly intense and rewarding time of the practice....

I feel a deep resonance within myself and with colleagues, and this helps me notice and appreciate each encounter more fully. The most interesting and amazing impact for me is the change I notice in other people especially teachers on my staff. 
Everyday I encounter people who treat me differently from the way they have treated me since I came to the school a year and a half ago. I do not believe that they have all changed. I have changed one aspect of my life. I have taken time to be in a state of pure awareness each day. . . This is not only changing the way I think and feel, but it is making me more approachable. Today my principal told me that I was not as intense as I used to be.

\section{Follow-up Study}

This study described here was conducted as a follow up to people who had done the meditation in one of the course mentioned above. The study focused on the following questions.

1) What is the nature of your meditation practice? (e.g. type and frequency)

2) Have you engaged in any meditation instruction since the class?

3) What have been the effects of your practice on your personal and professional life?

4) Have you experienced any difficulties or problems with the practice?

Letters were sent out to 182 former students asking if they would be interested in participating in an interview related to the questions above. Because the study involved a face to face interview the study was limited to former students living in the Toronto area. From this group forty letters were returned because the student had moved. In the end 
twenty-one former students (17 women and 4 men) agreed to participate. Of the twentyone, eleven were teachers at the elementary or secondary level, four were teaching at the post-secondary level, four were administrators and two were consultants.

The participants were interviewed by the junior author. The interview lasted between 30 minutes and one and one-half hours. To triangulate the data the following material was also collected:

1) meditation journals from the course,

2) summary reflections on the meditation submitted as part of the course,

3) the interviewer's reflections on the interviews.

In reporting the data, the main findings and themes are reported as well presenting profiles of two participants.

\section{Nature of the meditation practice}

For the large majority of individuals (19 of 21) introduction to meditation came in the course; however, two individuals had already been meditating when they enrolled in the course. One person had taken the course seven years ago while seven had taken the course as recently as two years ago. The average length of time for meditating for the participants was a little over four years.

Most of the participants reported using more than one meditation technique. The most popular technique used by ten participants was meditation on the breath. Mantra was used by eight participants. Seven people indicated that they used some form of mindfulness or movement (e.g. walking) meditation. One woman said: "So for me it's capturing a moment during the day, be it in the morning before I get ready for the day, or 
being the shower ... So, it's being in a meditative state of awareness." Six participants used visualization in their practice. Six also connected their meditation to their religious practices such as using a quote from the Bible to focus on in their meditation. One man commented: "I'd go to the Bible. And you know, there's lots of nice verses I the Bible in terms of being suitable to a mantra." Finally, five stated that they do some form of lovingkindness meditation. One man said: "So, when I sit in any transit and I see people around, or when I move in the traffic and I see other people around, it gives me joy to meditate and wish those people well."

The frequency and length of time committed to meditation varied. Thirteen participants (62\%) stated that they meditate every day. Three said they meditate 2-5 times a week. Finally three indicated that they meditated sporadically, or when they feel the need. Regarding length of the meditation, one was meditating at least two hours everyday. Three were meditating from 45-minutes to one hour. Most indicated (9), or 43\%, that they meditate about 20-30 minutes. Finally two said that meditate 15 minutes or less.

Only four of the participants indicated that they sought additional instruction after the courses. Two individuals went on retreats and the other two sought additional instruction from individuals.

The only problems that people indicated that they were having was making the time for meditation or being disciplined enough to do it on a daily basis. Only one person indicated that they had real problems with their meditation practice. She felt the meditation contributed to an emotional collapse along with some other factors in her life: 
Now to be fair, I was also. . .moving into menopause, and . . .things were changing radically where I teach, they'd just eliminated the English department, so I had external things.

This person found a Buddhist meditation teacher who had her focus more on the body in her meditation. Now she does not do sitting meditation practice although she does a lot of reading in spirituality and she believes that some of her activities such as singing and listening are meditative. She feels there are dangers in doing unsupervised meditation practice.

\section{Effects of Meditation Practice}

All the participants except one commented on the positive effects of the practice on their personal and professional lives.

\section{Personal Effects.}

The majority of participants 13 or $62 \%$ commented on how the meditation had helped them become calmer and more relaxed. Some of the comments included:

"I've noticed I'm calmer. I'm much calmer.” (female vice-principal)

"There is a sense of feeling more centered, more whole, calmer, more peaceful, more contented, or grounded." (male teacher) 
"I'm not as agitated. . or I'm not as arousable from the point of view that things don't bother me as much. ... I feel calmer, I feel more. . . this word centered keeps coming to mind." (female nursing professor)

A few participants talked about how the process of being mindful brought calmness into their daily life.

"The mindfulness also is very powerful concept for me. It's really helping. It changed my life a lot... . I know that I'm less anxious and I'm less worried." (female teacher)

"I will go into the park and I will park the car and I will just stare out at the trees. And I will just open the window so I hear the natural sounds. I don't have the radio on. And just become conscious of my breathing. " (male consultant)

"I find these little moments kind of funny when they happen because all of a sudden I become very aware that I'm washing the dishes or vacuuming. . . . And I kind of get into the moment, and it stays with me during the day. (female adminstrator)

Another main effect noted by five participants was that they felt that the meditation softened them or made them more gentle. One female teacher who does walking meditation commented: 
It makes me gentle. And I also find that I'm feeling angry or upset about something, and then I walk, then by the end of the walk - it doesn't carry the same power over me anymore.

Another woman stated: "It made a difference in softening me in my home, in my personal life in terms of working through the process with my husband and, you know, how do you solve this?" (female principal)

Finally, five participants felt that the meditation had helped them with personal relationships. One female administrator commented: "It affects all your relationships. They're better. They're deeper." A male consultant found that people come to him for help. "Well a lot of my friends, they phone me for advice. I'm sort of like their counselor, because once you get into that whole realm of awareness and meditation and looking at things in perspective. .."

\section{Professional Effects}

Again more than half the participants commented on how the meditation helped them be calmer in the workplace. One principal commented how calmness is important to the whole process of change, "And to get any kind of change happening in schools, it's imperative that people are calm and are in an almost meditative state in order to make those changes that are being demanded." This principal runs meetings that don't have an agenda so that "We're just here to talk about the work that we're doing, and enjoy each 
other." She adds this is "not team building, it's just kind of being together, it doesn't have a name."

A related effect is that the participants commented that they are not as reactive as they step back from troublesome situations.

You can get really frustrated with these kids because these kids get really angry and frustrated because they can't read, and your first response is to be an authoritarian, when actuality they just need to be hugged and loved. So it (the meditation) really helps me to step back and look at what really is going on. (female teacher)

Another teacher simply said "I don't remember the last time I raised my voice." She added that one of students told her "Miss, how come you're so calm all the time?"

One of the most interesting effects was the way four of the teachers integrated the meditation into their teaching. One teacher who teaches grade 5 and 6 along with grade 8 drama says:

"I've been doing it now since Jack's course, so I've been doing it for three years, with all the kids, especially in drama, the meditation's amazing, and they love it, they ask me now. . . They'll come in. . and now my students ask me, "Can we meditate, we're really hyper." Or "Can we meditate before the test?"

This teacher has the students focus on the breathing as a way to focus and relax. She also has them visualize going to the beach or lying on a cloud. She also integrates the 
visualization with her teaching so that if they are reading a novel in class she will have them imagine some aspect of the story. In studying ancient civilizations she had them close their eyes and see the pyramids and feel sand blowing on their faces. She sees the impact in their art and poetry. "I mean I've never seen such poetry. Just with more colorful vocabulary. Colorful words, colorful language."

Another teacher at the high school has introduced meditation to approximately 1500 students. She teaches in the Catholic system and in seven years she has never received a complaint from a parent. She explains how she introduces meditation:

I first create a very safe environment in my class, so people feel very comfortable. ... And then we get to a point where I'm saying, "Now there's a different way to pray. Usually, in our tradition, we mean we need to talk to God, or to the Higher Spirit, but sometimes we need to sit and listen ... . So this is a form to connect with your spirit". . . And I have my students journal as well. So I ask for journal reflections and they're very powerful. And now word gets around, because people come to my class the first day and say, "Are we going to meditate today?'

A teacher who works with students training to be teachers has attempted to integrate the mindfulness and lovingkindness into his teaching. He says "I'm encouraging my classes to take joy in the tasks that not necessarily glamorous. . . and the whole loving-kindness notion is that any kind of direction you give is simply a suggestion in loving way. 
Another individual who taught Grades 4 to 8 in the Catholic system also introduced meditation to her students. Like the secondary school teacher, she connected the meditation to prayer. She found that if she missed a day of meditation the students would insist on doing it. She said that the supply teacher who took over her class told the principal that her classes were always very calm.

And I'm not a very calm type of teacher. I'm a very active kind of teacher, and I have everybody doing different things. . . . But I'm sure it's meditation, I can't prove it, but I'm sure it's that thing that brings us together. And it connects-you connect on a different level, you know not just the intellectual. But you connect on a spiritual level and when we were like that in our classroom the supply teacher would notice: This is a very calm classroom.

\section{Profiles}

\section{Claire}

Claire first took the course in 1993. Claire is a special education teacher at the intermediate level. Below are some excerpts from her journal from that course. She starts by focusing on the breath and counting the breath. Like most beginners, the first weeks were sometimes frustrating for Claire. 
Distracted! I don't get this. . .my environment is certainly cooperating, a silent house, my dog curled at my feet. I try to maintain focus, finding the counting to be a comforting anchor but after a few breaths I find myself fidgeting

For the rest of the course she practiced visualization and some walking meditation which is the meditation that she does today. In a later entry she notes: "It feels like whatever I do I am doing it bigger, or more, or deeper or something-especially walking. . it is strong and rhythmic with my movement and my breathing synchronizing."

Now Claire walks almost everyday for 45 minutes. She usually takes her dog for the walk. When she begins the walk, she often prays for ten minutes or so about issues that are confronting her that day. The prayer usually also includes thanking God for the blessings in her life. After that she settles into a rhythm for the rest of the walk:

I get a pace with my walking that matches my breath so that it's just a comfortable, familiar place that I know. I know when I've hit it. It's just the way the breath goes in and comes out is at peace with the way that I walk. And when I get to that place, I feel that's the part where I feel myself becoming still. She describes this place further: I just feel the process brings me to a place of gratitude, brings me to a place of peacefulness, and calm and stillness. And also to place where I feel I'm enough, that I' $m$ just fine, that I'm enough. 
The walking meditation has become part of Claire's life. She says: "It carries its own momentum. When you practice it becomes easier to practice. Because once you're doing it, and you set that time aside and you honor it, you get used to having it. The longing for it."

Claire feels that the walking meditation helps her feel grounded in her work. She says: "I interact with others more calmly, more gently, more compassionately" Claire works with kids that have behavioral difficulties who are often angry. She notes: "I feel a patience with them and tenderness towards them. . . The kid is being rude-driving me crazy. Instead, I see the kid is hurting and I care for him differently. I think I see the student as myself.

Claire also works on being mindful in the classroom being present to her students. The meditation and mindfulness helps bring Claire to a deep sense of connectedness:

And that place of gentleness, and presence, and mindfulness, breathing and really living in some healthy way of connecting, well, it connects you with yourself, but it also connects you to those around you. I mean there's a sense of common soul. There's just a sense that we are all just one.

Mary

Mary is counselor and special needs consultant working in a community college. She works with students who have learning disabilities. 
Mary took the course in 1995. Her meditation practice is inisight, or vipassana, which is a meditation that starts with the breath as a focus but gradually expands the focus to whatever is arising in the moment(e.g. sounds, thoughts, sensations, feelings.) After starting the practice, Mary has faced a battle with cancer. She then supplemented her vipassana meditation with visualization where she would imagine the healthy cells battling the cancerous cells. Eventually though she has just returned to the vipassana meditation.

Mary meditates for about thirty minutes three or four times a week but also when she is feeling stress. For example she meditated on the operating table before her surgery for cancer. She has also meditated in special places such as the Grand Canyon and Pacific Ocean. Mary has supplemented her practice by attending a meditation retreat and also a program that included meditation offered at the hospital where she has been treated for the cancer. Mary also practices Chi Gong which is a form of movement meditation.

Mary feels meditation has had a deep impact on her life. She says: "It's totally affected my personal life. It's enabled me to live in the present... I find when I go for a walk now, I am so busy looking at everything that's around me and I'm not thinking." Mary sees the impermanence of things including her own thoughts. She finds it helpful to name thoughts as they arise so that if she has an angry thought she will label that thought "angry". This process helps her let go of negative thoughts.

In her work she finds also that she is also much more present to students when they come to her. She also finds that she is more compassionate and believes that both the meditation and her illness have led to the compassion. She also feels that her ego does not get in the way in the workplace. For example, someone who is actually below her in the college hierarchy was telling her how to do her job. While other coworkers resented this, 
she said it didn't bother her at all. She also finds now that she simply wants the best for everyone she meets and works with.

I never think someone has more than I have or someone is better off, even people who are well. I don't begrudge them their health anymore, I'm happy for them. And so the meditation may have helped here, because you become one of the larger whole that happens. . . Meditation has made me better able to show love to other people. You know I was quite reserved before. Again the illness and meditation have probably contributed here.

Mary also recites a poem that she finds helpful in her daily life.

I have arrived, I am home,

In the here, in the now

I am solid, I am free

In the ultimate I dwell.

\section{Conclusion}

A large amount of data supporting the effectiveness of meditation has been collected. (Walsh, 1999) These benefits include physical ones such as lowering blood pressure and cholesterol levels (Murphy and Donovan, 1997). Studies have also found that meditation can increase creativity, academic achievement and interpersonal relationships. (Alexander et. al., 1991; Murphy and Donovan, 1997). This study was congruent with this 
general research literature. The major finding of this study is that when meditation is introduced in an academic setting it can have positive long term effects on both the personal and professional lives of educators. Most of the participants felt that meditation helped them become calmer and more grounded in their life and work.

Another findings was a ripple effect as about one quarter of the teachers introduced meditation to their students. They found that students looked forward to the meditation and help make their classes calmer and more relaxed. One teacher felt that it also improved their creativity.

Much of learning that occurs in a university setting and in teacher education programs is limited to the intellect. It is possible, however, to introduce spiritual practices into academic environments in a non threatening manner that can have long term holistic effects. In education we often cite the need to teach the whole person, yet the methods we employ are almost entirely focused on the intellect. One student discussed the effects of meditation in very strong terms:

So in a nutshell, what has meditation done for me? It has changed my life. When I was sick I might have died, it taught me to heal myself. It has connected me with wisdom that goes far, far beyond what is written in any book. . . It's really our lifeline to peace, harmony and clarity.

Not all of the participants commented this strongly about the impact of meditation but it is clear that meditation had made a significant different in their work and lives. 


\section{References}

Alexander, , C. Rainforth, M. \& Gelderloos, P. (1991) Transcendental Meditation, self actualization, and psychological health: A conceptual overview and statistical metaanalysis. Journal of Social Behavior and Personality 6, 189-247.

Benson, H. (1976) The relaxation response. New York: Avon.

Griffin, R. (1977, February) Discipline: What's it taking out of you? Learning, pp. 77-80.

Miller, J. (1993) The holistic teacher. Toronto: OISE Press.

Miller, J. (1994) The contemplative practitioner. Toronto: OISE Press.

Miller, J. (1995) “Meditating teachers” Inquiring Mind 12:19-22.

Murphy, M. \& Donovan, S. (1997) The physical and psychological effects of meditation. Sausalito, Calif.: Institute of Noetic Sciences.

Walsh, R. (1999) Asian contemplative disciplines: Common practices, clinical applications and research findings. Journal of transpersonal psychology. 31:83-108. 